\title{
Commentary: Socially or materially marginal children are less likely to be fully immunised-a systems response
}

Peter Crampton, Julia Carr

Department of Public Health, University of Otago Wellington School of Medicine and Health Sciences, PO Box 7343 , Box 7343,
Wellington, New Zealand

Peter Crampton head of department Service Planning and Funding Directorate, Capital and Coast District Health Board, Private Bag 7902, Wellington, New Zealand

Julia Carr senior portfolio manager primary care Correspondence to: P Crampton peter.crampton@ otago.ac.nz
Samad and colleagues have neatly shown what we already know: children born into circumstances that are socially or materially marginal are less likely to be fully immunised. ${ }^{1}$ At age 9 months immunisation rates in the UK are high ( $>95 \%$ fully immunised); the challenges posed by Samad et al's paper are the challenges associated with reaching that last small percentage of children. This is in the context of the UK healthcare system, which is universal and doesn't impose user charges. Samad et al have shown also that children who are unimmunised fall into two groups: those from disadvantaged backgrounds and those with mothers who were on average older and more educated.

The first barrier to overcome is the framing and labelling barrier; the term "hard to reach," along with its semantic equivalents, is service-centric and an implicit admission of the system's failure, which in turn invites nihilism. "Hard to reach" thinking tends to transfer ownership of the problem to the victims of the problem, thereby taking the focus away from the role of the primary care system. A number of primary care approaches to immunisation have been shown to be effective.

Because poor populations tend to be more mobile, special attention needs to be paid to outreach and opportunistic immunisation. However, outreach on its own may not be sufficient: overall primary health care and social service capability are important too. Schuster et al found that home visiting alone was only partially effective and suggested that case managers may be more effective when they have resources to use to help overcome specific barriers. ${ }^{2}$ Opportunistic and outreach immunisation in turn need to be supported by a shared immunisation register. ${ }^{3}$

Opportunistic immunisation is equally important. It is likely that partial immunisation may be contributed to by missed opportunities, such as inappropriate delaying of immunisation after a hospital admission. ${ }^{3}$ It is important for hospitals to ensure that immunisations are given before discharge and that correct information is freely available as to what constitutes a contraindication. Likewise, immunisation update should be offered at all primary care contacts.

In order to address belief systems and conflicting information, tailored approaches to information are required for the unimmunised (for example, those of black Caribbean ethnicity). ${ }^{3}$

Finally, most importantly, the foundation for an effective immunisation system is the recognition that the most powerful and persistent barriers to timely immunisation are poverty and factors associated with poverty. ${ }^{3}$ In order to engage successfully with socially marginalised communities, and the health problems that typically occur in such communities, primary care needs to include in its remit intersectoral approaches to addressing poverty. Along with this, primary care needs to be underpinned by a community development approach which defines health in the context of social factors such as housing and the economy, acknowledges that health improvements do not necessarily start with health services, focuses on community wants, and takes a bottom-up approach. ${ }^{5}$

\section{Competing interests: None declared.}

Samad L, Tate AR, Dezateux C, Peckham C, Butler N, Bedford H. Differences in risk factors for partial and no immunisation in the first year of life: prospective cohort study. BMJ 2006;332:1312-3.

2 Schuster M, Wood D, Duan N, Mazel R, Sherbourne C, Halfon N. Utilization of well-child care services for African-American infants in a low-income community: results of a randomized, controlled case management/home visitation intervention. Pediatrics 1998;101:9991005 .

National Vaccine Advisory Committee. Strategies to sustain success in childhood immunizations. JAMA 1999;281:363-70.

Bond L, Nolan T. Vaccine preventable diseases and immunisations: a qualitative study of mothers' perceptions of the severity, susceptibility, qualitative study of mothers' perceptions of the severity, s

5 Haglund B. The community diagnosis concept-a theoretical framework for prevention in the health sector. Scand J Prim Health Care Suppl for prevention in
$1988 ; 1: 11-21$.

\section{A shaky moment}

As a specialist registrar in a tertiary centre in Belfast, I was the on-call cardiologist one Sunday when I was bleeped by a senior house officer in the emergency department to review a patient as soon as possible. The patient was a 70 year old man who had been admitted with an episode of syncope. He had gone to church that morning and fainted. This was associated with nausea and sweating, but he had recovered within a couple of minutes.

The patient thought that it was one of those simple faints which he had experienced before, but electrocardiography in the emergency department showed episodes of narrow complex tachycardia, although haemodynamically he was fine. I rushed to emergency and looked at the monitor which showed the rhythm (figure).

I was perplexed for a moment until I noticed the tremor in the patient's hands. I realised at once that the monitor was tracing the rate of tremor rather than heart rate. I checked the pulse, which

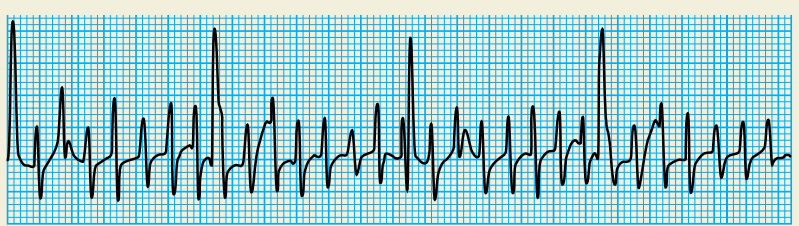

corresponded with the rate of the big complexes coming in between the small complexes. I changed the lead position, removing the hand electrodes and replacing them with electrodes on the chest wall-the arrhythmia disappeared. Artefacts can sometimes be so baffling.

Debjit Chatterjee staff grade cardiologist, Wexham Park Hospital (debjit_1967@yahoo.co.uk) 